\title{
Entomologic investigation of Plasmodium knowlesi vectors in Kuala Lipis, Pahang, Malaysia
}

\author{
Adela I Jiram ${ }^{1,2}$, Indra Vythilingam²*, Yusuf M NoorAzian', Yusri M Yusof ${ }^{1}$, Abdul H Azahari ${ }^{3}$ and Mun-Yik Fong ${ }^{2}$
}

\begin{abstract}
Background: The first natural infection of Plasmodium knowlesi in humans was recorded in 1965 in peninsular Malaysia. Extensive research was then conducted and it was postulated that it was a rare incident and that simian malaria will not be easily transmitted to humans. However, at the turn of the 21st century, knowlesi malaria was prevalent throughout Southeast Asia and is life threatening. Thus, a longitudinal study was initiated to determine the vectors, their seasonal variation and preference to humans and macaques.

Methods: Monthly mosquito collections were carried out in Kuala Lipis, Pahang, peninsular Malaysia, using human-landing collection and monkey-baited traps at ground and canopy levels. All mosquitoes were identified and all anopheline mosquitoes were dissected and the gut and gland examined for oocysts and sporozoites. Nested polymerase chain reaction (PCR) was conducted on positive samples, followed by sequencing of the csp gene.

Results and discussion: Anopheles cracens was the predominant mosquito biting humans as well as the macaques. It comprised $63.2 \%$ of the total collection and was the only species positive for sporozoites of P. knowlesi. It was exophagic and did not enter houses. Besides An. cracens, Anopheles kochi was also found in the monkey-bait trap. Both species preferred to bite monkeys at ground level compared to canopy.

Conclusion: Anopheles cracens, which belongs to the Dirus complex, Leucosphyrus subgroup, Leucosphyrus group of mosquitoes, has been confirmed to be the only vector for this site from Pahang during this study. It was the predominant mosquito at the study sites and with deforestation humans and villages are entering deeper in the forests, and nearer to the mosquitoes and macacques. The close association of humans with macaques and mosquitoes has led to zoonotic transmission of malaria.
\end{abstract}

\section{Background}

Malaria still poses a public health problem in Malaysia despite continuous efforts to control the spread of the disease. Four species of Plasmodium were responsible for the spread of malaria in humans for a long time. However, currently the fifth species, Plasmodium knowlesi, which is also life threatening [1], has spread to many parts of Malaysia [2-4]. Besides Malaysia, knowlesi malaria has also been reported in countries in Southeast Asia. These include Thailand [5], Singapore [6], Philippines [7], Vietnam [8], Myanmar [9,10], Indonesia [11] and Cambodia [12]. This disease has also been reported in Europe and America by travellers who

\footnotetext{
* Correspondence: indra.vythilingam@gmail.com

${ }^{2}$ Parasitology Department, Faculty of Medicine, University of Malaya, 50603, Kuala Lumpur, Malaysia

Full list of author information is available at the end of the article
}

visited endemic sites in Southeast Asia, particularly Malaysia [13-17].

The first reported case of human knowlesi malaria in Malaysia was from Pahang. An American surveyor working in the jungles of Pahang contracted the disease [18]. Work was then carried out to determine the epidemiology of the disease and its vectors [19-23]. No further cases were detected in spite of screening more than 1,000 people in that area. No vectors were incriminated in that area during their study [21]. The main aim of the investigation was to determine if malaria was a zoonosis. Studies were also conducted in other areas of peninsular Malaysia. New species of simian malaria in macaques were described [24-26] and Anopheles hackeri was incriminated as the vector of P. knowlesi [23]. However, An. hackeri was found biting only macaques and was not attracted to humans. Thus, from the studies it was

\section{Biomed Central}


hypothesized that $P$. knowlesi will not be easily transmitted to humans and that the first case was an extremely rare event.

In peninsular Malaysia, malaria, which is transmitted largely by Anopheles maculatus is on the decline. However, cases of P. knowlesi are occurring in areas which have been free of malaria [3]. Early studies have incriminated the Anopheles Leucosphyrus group of mosquitoes as the vectors of simian malaria [21,27]. The epidemiology of knowlesi malaria is thus strongly linked to the Leucosphyrus group of mosquitoes. Recently Anopheles latens has been incriminated as a vector of P. knowlesi in Kapit, Sarawak Malaysian Borneo [28] and Anopheles cracens as the vector in Kuala Lipis Pahang, peninsular Malaysia [3]. The results of a longitudinal study to understand seasonal variation in two different ecotypes in Kuala Lipis is presented here.

\section{Methods}

\section{Study sites for mosquito collection}

The study was carried out in Kuala Lipis district in Pahang State, peninsular Malaysia. Three sites were selected for adult mosquito collection based on the presence of macaques and the occurrence of malaria cases. One was Serunai Mela Village $\left[4^{\circ} 7.0^{\prime} \mathrm{N}, 102^{\circ}\right.$ $\left.11.9^{\prime} \mathrm{E}\right]$. This area was at the edge of the forest and there were only two houses situated in that area, which were $300 \mathrm{~m}$ apart. Both houses were surrounded by trees and long-tailed macaques frequent the area. Towards the end of the study, parts of the forest were being cleared to build roads. The second site was a fruit orchard in Sungai Ular [ $4^{\circ} 15.7^{\prime} \mathrm{N}, 102^{\circ} 4.8^{\prime} \mathrm{E}$ ]. This is a huge area with large trees on undulating land. Access to this area was controlled. More macaques were sighted in this area compared to the forest edge. The third site was in Sg Ular village [ $4^{\circ} 12.673^{\prime} \mathrm{N}, 101^{\circ} 53.127^{\prime} \mathrm{E}$ ] where indoor and outdoor collections were carried out for three months. The houses in the villages were fairly close to each other and each house had its own yard planted with flowering plants and fruit trees.

\section{Mosquito collection}

A 12-hour bare leg catch (BLC) [29] was carried out from August 2007 to August 2008 (with the exception of December 2007). Four nights of collections were carried out in each area every month by three men working in two shifts outdoors from 19:00 hours to 07:00 hours. The first shift was from 19:00 hours to 23:00 hours and the second from 23:01 hours to 07:00 hours. BLC was performed in the third site both indoors and outdoors by two men each from 19:00 to 23:00 hours. Indoor collection was discontinued after three months since no Anopheles mosquitoes were obtained indoors although they were biting outdoors and also partly due to shortage of manpower. It was carried out mainly to determine the presence of $A n$. cracens and the behaviour, as cases were reported from the village (unpublished document). All volunteers who carried out mosquito collections were provided with doxycycline as the antimalarial prophylaxis.

\section{Monkey-baited trap (MBT)}

In the forest (Serunai Mela), a study was conducted (simultaneously as BLC) to compare the mosquitoes attracted to human bait at ground level and monkey bait at ground level, and on platforms at $3 \mathrm{~m}$ and $6 \mathrm{~m}$, in the forest canopy. The platforms were constructed as described by Wharton et al. [30]. In brief, the platforms were constructed among the branches of trees to a height of $6 \mathrm{~m}$. Special metal cages measuring $90 \mathrm{~cm}$ x $90 \mathrm{~cm}$ x $90 \mathrm{~cm}$ and covered by chicken-wire were used to house the monkeys on the platform. In the first two months only one monkey (Macaca fascicularis) was placed in each cage but in subsequent months, two monkeys were kept in one cage. A mosquito net measuring $190 \mathrm{~cm} \times 180 \mathrm{~cm}$ $\times 150 \mathrm{~cm}$ with an opening of about $40 \mathrm{~cm}$ on either end were used to cover the monkey cages on each platform. The traps were operated from 19:00 to 05:00 hours and were searched at 21:00, 00:00 and 05:00 hours. A collector, upon entering the net, closed the opening and collected all resting mosquitoes with the use of aspirators. Mosquitoes in the aspirator were then transferred to paper cups and were brought to the laboratory for identification and dissection.

\section{Mosquito identification and dissection}

All mosquitoes were identified taxonomically in the field laboratory using a dissecting microscope. The keys of Reid [31] were used for the identification of Anopheles mosquitoes while the keys of Sallum [32] were used for the identification of Leucosphyrus group. Anophelines were dissected to extract the ovaries for the determination of parity and the midguts and salivary glands were examined for oocysts and sporozoites respectively. When sporozoites and oocysts were encountered, they were preserved in a $1.5 \mathrm{ml}$ microcentrifuge tube (Axygen, USA) containing absolute ethanol. The tubes were labelled accordingly and brought to the laboratory for molecular studies.

\section{DNA extraction for salivary gland and oocyst}

Prior to DNA extraction, ethanol used to preserve the oocysts and salivary glands were left to evaporate completely by placing the tubes in a Thermomixer (Eppendorf, Germany) set at $70^{\circ} \mathrm{C}$. DNA was extracted using the Qiagen DNeasy Blood and Tissue Kit (Hilden, Germany), following the manufacturer's recommendation. 


\section{Nested polymerase chain reaction (PCR)}

A nested polymerase chain reaction (PCR) assay described by Singh et al. [2,33] based on the Plasmodium sequence of the small subunit ribosomal RNA (SSUrRNA) was used to identify the species of malaria parasites found in the mosquito samples. The product from the first reaction (Nest 1) was used as the template for a second amplification (Nest 2). Positive controls for Plasmodium falciparum, Plasmodium malariae, Plasmodium vivax and P. knowlesi were included for all nested PCR species assays. A negative control from negative human blood was also included for every batch of the assays. The volume used for the Nest 1 reaction mixture was $50 \mu$ l. The PCR cocktail contained $1 \mathrm{X}$ reaction buffer (5X Green Go Taq Flexi Buffer, Promega Madison, USA), $3 \mathrm{mM} \mathrm{MgCl}_{2}$ (Promega), $200 \mathrm{mM}$ of each deoxynucleoside triphosphate (Promega), $300 \mathrm{nM}$ of each primer (rPLU1 and rPLU5) and $1.25 \mathrm{U}$ of Go Taq DNA polymerase (Promega) and $5 \mu$ l of DNA template was used for each reaction. Nest 1 amplification conditions were as follows: initial denaturation at $94^{\circ} \mathrm{C}$ for $4 \mathrm{~min}$; followed by 35 cycles of denaturation at $94^{\circ} \mathrm{C}$ for $30 \mathrm{sec}$; annealing at $55^{\circ} \mathrm{C}$ for $1 \mathrm{~min}$; extension at $72^{\circ} \mathrm{C}$ for $1 \mathrm{~min}$ and a final extension at $72^{\circ} \mathrm{C}$ for $4 \mathrm{~min}$. Two microliters $(2 \mu \mathrm{l})$ of the Nest 1 PCR amplification products were used as the DNA template for each of the $20 \mu \mathrm{l}$ Nest 2 amplification. Nest 2 reaction mixture contained $1 \mathrm{X}$ reaction buffer (5X Green Go Taq Flexi Buffer Promega), $2 \mathrm{mM} \mathrm{MgCl}_{2}$ (Promega,), $200 \mathrm{mM}$ of each deoxynucleoside triphosphate (Promega,), $300 \mathrm{nM}$ of each primers, and $0.5 \mathrm{U}$ of Go Taq DNA polymerase (Promega) and $2 \mu \mathrm{l}$ of the Nest 1 PCR products were used as DNA templates. Nest 2 amplification conditions were identical to those of Nest 1 except that the annealing temperature was $58^{\circ} \mathrm{C}$ for the species-specific primers (rFAL 1 and 2, rMAL 1 and 2, rVIV 1 and 2), $60^{\circ} \mathrm{C}$ for $P$. knowlesi primers (Pmk8 and Pmk9) and $62^{\circ} \mathrm{C}$ for the genus-specific primers (rPLU 3 and rPLU4). All PCR reactions were carried out using thermal cycler (Techne TC 152 -Barloworld Sci Ltd, UK). Eight microliters $(8 \mu \mathrm{l})$ of Nest 2 amplicons were loaded on a $2.5 \%$ agarose gel for $80 \mathrm{~min}$ at 80 volts using $1 \mathrm{X}$ TBE buffer. The gels were stained with ethidium bromide and were visualized under UV light.

\section{Sequencing of plasmodium circumsporozoite protein genes}

Sequencing of the circumsporozoite protein ( $c s p)$ genes were carried out on all four mosquito samples which were positive for P. knowlesi by nested PCR; isolates MO30SG, MO62SG, MO48SG and MO10MG. The csp genes were amplified using the protocol described [3]. The primers used were PKCSPF2 (5'TACAAGAACAAGATGARGAAC3') and PKCSPR2 (5'TCAGCTACTTAATTGAATAATGC 3’).
Phusion DNA polymerase (Finnzymes, Finland) was used for the PCR reaction. The size of the PCR product was approximately $1.2 \mathrm{~kb}$ and the amplicons from each isolate were excised from the agarose gel and purified using the QIAquick Gel Extraction Kit (Qiagen, Germany), following the manufacturer's recommendation. The purified products were cloned into pCR Blunt vector (Invitrogen, Carlsbad, CA, USA) and transformed into TOP10 competent Escherichia coli cells (Invitrogen) by heat shock. At least 20 of transformants from each PCR were screened using the $\operatorname{cs} p$ primers mentioned above. Amplification was done in $20 \mu$ reaction mixtures containing $1 \mathrm{X}$ reaction buffer (5X Green Go Taq Flexi Buffer, Promega Madison, USA) $2 \mathrm{mM} \mathrm{MgCl}_{2}$ (Promega), $200 \mathrm{mM}$ of each deoxynucleoside triphosphate (Promega), $300 \mathrm{nM}$ of each primers and 0.5U Go Taq DNA polymerase (Promega,). PCR conditions were as follows: initial denaturation of $94^{\circ} \mathrm{C}$ for $10 \mathrm{~min}$ followed by 30 cycles of amplification at $94^{\circ} \mathrm{C}$ for $1 \mathrm{~min}$, annealing at $53^{\circ} \mathrm{C}$ for $1 \mathrm{~min}$, extension at $72^{\circ} \mathrm{C}$ for $1 \mathrm{~min} 20 \mathrm{sec}$, followed by a final extension step at $72^{\circ} \mathrm{C}$ for $5 \mathrm{~min}$. Transformants with the correct band were grown in broth overnight. Plasmid DNA was extracted with the QIAprep Spin Miniprep Kit (Qiagen, Germany) following the manufacturer's protocol. Ten microliters $(10 \mu \mathrm{l})$ of the amplicons were digested with EcoR1 (Promega) and analysed by gel electrophoresis. Purified plasmids were sent to Solgent Co Ltd (Daejeon, South Korea) for sequencing to obtain the entire csp gene sequence of $P$. knowlesi. Two clones were sent for sequencing for each isolate with primers PKCSPF2 and PKCSPR2 [3].

\section{Analysis of sequence data}

The csp genes of isolates were successfully amplified, cloned and sequenced. The analysis of $c s p$ was performed as previously described by [2]. For the csp gene, sequences of the 456 nucleotides that encodes nonrepetitive $\mathrm{N}$-terminal (first 195 nucleotides of coding sequence) and C-terminal (the last 261 nucleotides of the csp gene coding sequence) region of the protein were aligned. The nucleotide sequences of the $c s p$ genes were aligned by CLUSTAL W using Megalign (Lasergene, DNASTAR, USA). The sequences were compared to those obtained from the GenBank data base [P. knowlesi from peninsular Malaysia (EU821335, EU821336, EU708437, EU687467, EU687468, EU687470), Sarawak Malaysian Borneo (AY327570, GU0025505), Thailand (JF923566); P. coatneyi (AY135360), P. cynomolgi (M15104), P. simiovale (U09765), P. simium (L05068), P. inui (GU002523), P. fieldi (GU002521), P. vivax (M34697), P. malariae (U09766), P. falciparum (K02194) and P. vinckei lentum (AF162331)]. Phylogenetic trees were performed by the neighbourjoining (NJ) method and was analysed using the Maximum 
Composite Likelihood method with 1,000 bootstrap replicates and was carried out using the MEGA version 4.0 software [34].

\section{Ethical clearance}

This project was approved by the Institute for Medical Research \& Ethical Committee, Ministry of Health, Malaysia.

\section{Results}

Species composition and spatial distribution of Anopheles species collected in different ecological sites

A total of 9,086 mosquitoes were obtained of which anophelines comprised $16.4 \%$, while $83.6 \%$ were culicines. A total of 1,487 anophelines belonging to 14 species were collected within the 12-month period of mosquito collections from study sites as shown in Table 1. Anopheles cracens was the predominant species comprising $63.2 \%$ of the total collection of both bare leg catch and monkey-baited trap in the study sites. The second predominant anopheline species was An. maculatus (19.6\%), followed by An. hyrcanus gr (4.4\%) and An. kochi (3.6\%).

\section{Species biting rate by ecological sites}

Table 2 shows the biting rates for the four most predominant anthropophagic species and compares them with the different ecological sites. There were differences between both species composition and abundance in different locations. Anopheles cracens was the predominant species found abundantly in both the forest and the fruit orchard but was higher in the fruit orchard compared to the forest.

\section{Biting cycles}

Anopheles cracens are outdoor biters (exophagic). The other anophelines too did not enter houses. Anopheles cracens were early biters and come to bite man as early as 19:00 hours (Figure 1). The peak biting period was from 20:00 to 21:00 hours. Seventy four \% of the $A n$. cracens came to bite before 21:00 hours while 61\% of An. maculatus was found biting after 21:00 hours. This was significantly different $(\mathrm{P}<0.05)$.

\section{Seasonal changes in biting rate and parous rate}

Figure 2 shows the average bites/man/night and parous rate of $A n$. cracens and An. maculatus in relation to rainfall. The nearest meteorological station was located at the Department for Aborigine Affairs in Kuala Lipis. Since meteorological data were available only at a central location and it has been observed that it rains in both places at the same time thus, the data for both areas have been combined. The biting peak of An. cracens was in November 2007, January and March 2008. Heavy rainfall followed by dry spell appears to be ideal for the breeding of $A n$. cracens. However, there was no significant correlation between rainfall and abundance of $A n$.

Table 1 Anopheline mosquitoes collected from different collections sites in the district of Kuala Lipis, Pahang

\begin{tabular}{|c|c|c|c|c|c|c|}
\hline \multirow[t]{3}{*}{ Anopheles species } & \multicolumn{5}{|c|}{ Number collected at } & \multirow[t]{3}{*}{ Total (\%) } \\
\hline & \multirow[t]{2}{*}{$\begin{array}{l}\text { Sg Ular } \\
\text { (Fruit Orchard) }\end{array}$} & \multicolumn{2}{|c|}{$\begin{array}{l}\text { Kpg Serunai Mela } \\
\text { (Forest)* }\end{array}$} & \multicolumn{2}{|c|}{ Village house ${ }^{* *}$} & \\
\hline & & $\mathrm{BLC}$ & MBT & Indoor & Outdoor & \\
\hline An. aconitus & 3 & 0 & 0 & 0 & 21 & $24(1.6)$ \\
\hline An. barbirostris $g p$ & 5 & 12 & 14 & 0 & 6 & $37(2.5)$ \\
\hline An. cracens & 648 & 179 & 73 & 0 & 40 & $940(63.2)$ \\
\hline An. hyrcanus gp & 1 & 45 & 17 & 0 & 3 & $66(4.4)$ \\
\hline An. kochi & 1 & 2 & 51 & 0 & 0 & $54(3.6)$ \\
\hline An. leucosphyrus gp & 3 & 0 & 2 & 0 & 0 & $5(0.3)$ \\
\hline An. maculatus & 203 & 61 & 3 & 0 & 25 & 292 (19.6) \\
\hline An. philippinensis & 7 & 6 & 0 & 0 & 4 & $17(1.1)$ \\
\hline An. pujutensis & 1 & 0 & 1 & 0 & 0 & $2(0.1)$ \\
\hline An. separatus & 3 & 6 & 2 & 0 & 0 & $11(0.7)$ \\
\hline An. tessellatus & 5 & 8 & 7 & 0 & 5 & $25(1.7)$ \\
\hline An. umbrosus & 0 & 1 & 1 & 0 & 0 & $2(0.1)$ \\
\hline An. vagus & 0 & 1 & 0 & 0 & 0 & $1(0.1)$ \\
\hline An. karwari & 2 & 8 & 1 & 0 & 0 & $11(0.7)$ \\
\hline Total (\%) & $882(59.3)$ & $329(22.1)$ & $172(11.6)$ & 0 & $104(7.0)$ & 1487 \\
\hline
\end{tabular}

* MBT and BLC methods were used to collect mosquitoes at the forest while only BLC method was used to collect mosquitoes at other sites.

** Indoor and outdoor collections were only carried out for three months since no anophelines were obtained from indoor collections we discontinued due to manpower constraint. 
Table 2 Human biting rate (bites/man/night) of the 4 predominant anthropophagic species in different ecological sites

\begin{tabular}{llllll}
\hline Ecological sites & Person nights & Anopheles cracens & Anopheles maculatus & Anopheles philippinensis & Anopheles tessellatus \\
\hline Fruit Orchard & 156 & 4.15 & 1.30 & 0.04 & 0.03 \\
Forest & 144 & 1.24 & 0.42 & 0.04 & 0.06 \\
Outdoor & 36 & 1.11 & 0.69 & 0.11 & 0.14 \\
\hline
\end{tabular}

cracens (using Pearsons correlation) $(\mathrm{r}=0.12, \mathrm{P}>0.05)$ and An. maculatus $(\mathrm{r}=0.0 .25, \mathrm{P}>0.05)$. In most months the parous rate was more than $60 \%$.

\section{Monkey-baited trap}

A total of 172 anophelines were caught in the monkeybaited trap (Table 3). Anopheles cracens and An. kochi were the predominant mosquitoes found attracted to macaque monkeys. Anopheles cracens was more attracted to monkeys at ground level and $3 \mathrm{~m}$ from 19:00 to 00:00 hours. However, from 00:00 to 05:00 hours, An. cracens was more attracted to the monkeys at canopy level $(6 \mathrm{~m})$ compared to earlier collections at the same level. Anopheles kochi was predominantly biting at ground level. Based on the results from this study, the biting ratio of monkey to human of An. cracens is $1: 2.6$ and for An. kochi is 1:0.04

\section{Infection rates in anopheles}

Three An. cracens were found positive for sporozoites of which two were from human bait collection and one from monkey bait collection. One was positive for oocyst. In both study sites, sporozoite-infected $A n$. cracens were obtained. Only one An. cracens had both oocyst and sporozoites. Three of the sporozoite infections were P. knowlesi. The risk of infection was high during the particular month (November 2007 and January 2008) when infected mosquitoes were found as shown in Table 4.

\section{Parous rate, probability of survival, life expectancy and} vectorial capacity

The parous rates of $A n$. cracens and the confidence interval are shown in Table 5 . More than $60 \%$ of $A n$. cracens were parous, and $31 \%$ of these would be expected to live the 10 days necessary for the P. knowlesi sporozoites to be formed. Those would have a further life expectancy of 8.6 days. However, the vectorial capacity was higher in fruit orchard compared to the forest due to higher biting rate. Vectorial capacity was calculated according to Garrett-Jones and Shidrawi [35].

\section{Analysis of the csp genes sequencing}

The csp genes of malaria parasites, from the P. knowlesi isolates were successfully amplified, cloned and sequenced. All sequences for csp clones from four mosquito isolates were aligned and compared with four human malaria and all simian malaria species. The target size for PCR product ranges from 1,028 to $1,200 \mathrm{bp}$. Nucleotide sequences obtained were compared with other reference sequences by using the nucleotide BLAST to find significant matches. The sequences from the mosquito samples [JQ864243, JQ864244, JQ864245, JQ864246 JQ864247 and JQ889326] showed similarity with the monkey and human samples from the east coast region of peninsular Malaysia and Sarawak (Figure 3).

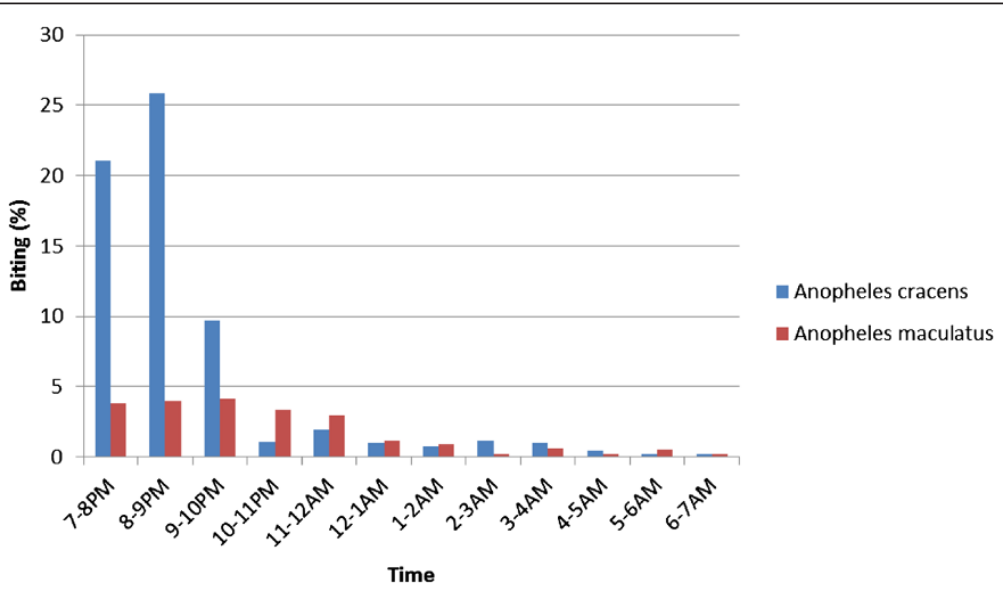

Figure 1 Biting cycles of Anopheles cracens and Anopheles maculatus in study sites. 

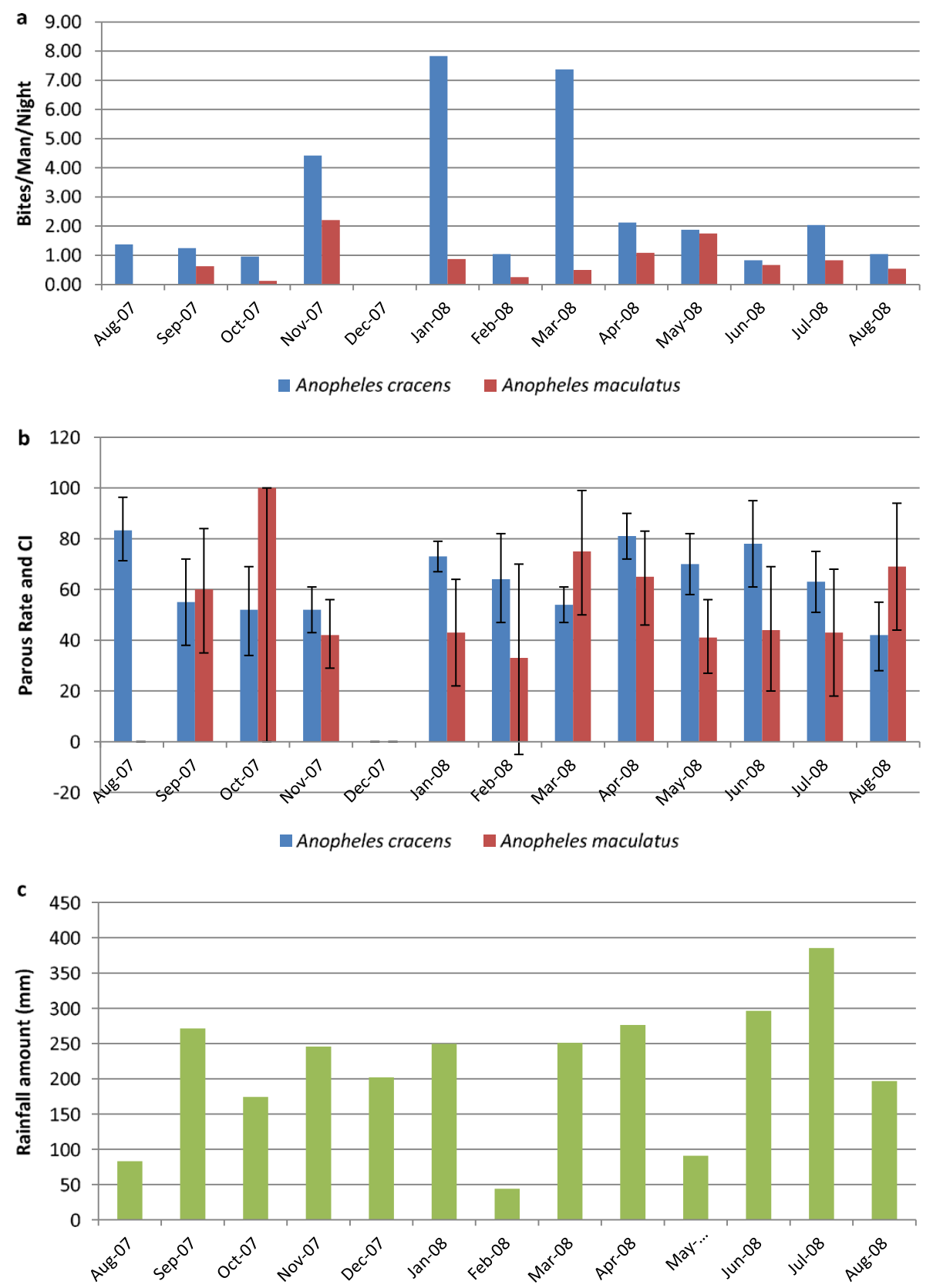

Figure 2 a) Man biting rate of Anopheles cracens and Anopheles maculatus in study sites, b) Monthly parous rate and Confidence Interval for Anopheles cracens and Anopheles maculatus in study sites and c) Rainfall amount from August 2007 to August 2008 (Department of Orang Asli Affairs of Malaysia Meteorological Station, Kuala Lipis).

\section{Discussion}

Knowlesi malaria is an emerging zoonosis of public health importance in Malaysia. Owing to Malaysia's rapid development, tropical climate, presence of vectors and long-tailed macaques, timely and effective disease control is required to prevent the spread of the disease. Since the emergence of knowlesi malaria in the country in 2004 [2], entomological investigations have been carried out to elucidate the vectors. Anopheles latens and $A n$. cracens have been incriminated as the vectors in Kapit, Sarawak [28] and Kuala Lipis, Pahang [3] respectively. Both these species are members of the An. leucosphyrus subgroup of mosquitoes known to be natural vectors of simian malaria. Species belonging to this group are also important vectors for human malaria and are distributed in the South and Southeast Asia region 
Table 3 Numbers of Anopheles cracens and Anopheles kochi caught at different heights in relation to the time of collection in MBT in Mela village

\begin{tabular}{|c|c|c|c|c|c|c|c|}
\hline HEIGHT & TIME & & & & & & TOTAL (\%) \\
\hline & $1900-2100$ & & $2100-0000$ & & $0000-0500$ & & \\
\hline & Anopheles cracens & Anopheles kochi & Anopheles cracens & Anopheles kochi & Anopheles cracens & Anopheles kochi & \\
\hline Ground (0 m) & 15 & 25 & 12 & 6 & 10 & 11 & $79(63.7)$ \\
\hline $3 \mathrm{~m}$ & 9 & 2 & 8 & 2 & 5 & 1 & $27(21.8)$ \\
\hline $6 \mathrm{~m}$ & 0 & 0 & 4 & 4 & 10 & 0 & $18(14.5)$ \\
\hline TOTAL (\%) & 24 & 27 & 24 & 12 & 25 & 12 & 124 \\
\hline
\end{tabular}

[36-38]. Anopheles latens is also a predominant vector of human malaria in Sarawak and has widespread distribution there $[39,40]$. However, An. cracens has limited distribution in the northern state of Perlis [19], in the east coast state of Terengganu [32,41] and currently in Pahang. It was also reported from southern (peninsular) Thailand (Chumphon, Phangnga, Phattalung) [42], and Indonesia (Aceh, Sabang, Sumatra) [32]. Anopheles cracens, was found to be an important vector not only for human malaria, but was also positive for $P$. inui and $P$. cynomolgi [19]. This mosquito was found to be attracted to monkeys at canopy and humans at ground level [43]. However, the current study has shown that An. cracens is biting macaques more at ground level than at canopy. The propensity of An. cracens to bite monkeys at ground level or canopy, and humans, demonstrates the importance of this species in the transmission of knowlesi malaria. Due to changes in the ecosystem, the behaviour of the mosquito also seems to change. Although extensive vector studies have been carried out in Pahang in the 1980s and 1990s by researchers from the Institute for Medical Research, (Kuala Lumpur, Malaysia) [29,44,45] there have been no previous reports of An. cracens there. Earlier studies by Wharton et al. in other parts of Malaysia also show no reports of this species [22].

Studies carried out by Baimai [42] in Thailand showed that An. cracens was an anthropophilic species and peak biting activity was from 19:00 to 21:00 hours. Thus, it seems that $A n$. cracens has not changed its biting activity since similar times has been demonstrated in this study. In addition, $A n$. cracens was known to enter shelter but rarely rested on walls and readily exited after a bloodmeal. Anopheles cracens was an important vector of human malaria because it was involved in the human
Plasmodium transmission in areas where houses were close to the jungle [46]. After the 1960s very little is known about $A n$. cracens in Malaysia. The distribution of $A n$. cracens in peninsular Malaysia remains unknown, although cases of knowlesi malaria are reported from all states in Malaysia.

Despite high prevalence of simian malaria in macaques in Kuala Lipis [3], the infected mosquitoes obtained from the study were low. Thus, there is a possibility that other species besides An. cracens are involved in the transmission of simian malaria at least among macaques. Transect studies through the forest will determine the other species involved in transmission. Studies carried out in Kapit, Sarawak where a large number of knowlesi malaria cases were reported from that area, An. latens was incriminated as the vector and the monkey to human biting ratio was $1: 1.3$ [47]. In comparison to that, the monkey to human biting ratio for An. cracens was 1:2. From this study, it was observed that $A n$. cracens is attracted to both monkey and human. However, it prefers to bite humans compared to monkeys. This could possibly be the reason why there was fewer knowlesi malaria cases in peninsular Malaysia compared to Malaysian Borneo. The frequency of a man-monkey-mosquito natural cycle transmission is dependent upon the various hosts in the area of natural transmission. Anopheles hackeri was incriminated as the natural vector of $P$. knowlesi among the monkey population in peninsular Malaysia after the discovery of the first human case of P. knowlesi in Pahang [23]. However, An. hackeri is not attracted to humans and is zoophagic. Thus, at that time it was concluded that $P$. knowlesi would not be easily transmitted to humans due to the nature of that mosquito. Thus, it

Table 4 Man-biting rate, sporozoite rate, entomological inoculation rate, estimated mean inoculation per month and risk of receiving infection of Plasmodium knowlesi from Anopheles cracens in study areas

\begin{tabular}{llllll}
\hline Species & Study Site & $\begin{array}{l}\text { Months } \\
\text { (Sporozoite) }\end{array}$ & $\begin{array}{l}\text { Man-biting } \\
\text { rate (ma) }\end{array}$ & $\begin{array}{l}\text { Sporozoite } \\
\text { rate } \mathbf{s}(\mathbf{9 5 \%} \text { Cl) }\end{array}$ & $\begin{array}{l}\text { Entomological inoculation } \\
\text { rate (EIR) }\end{array}$ \\
\hline Anopheles cracens & Fruit Orchard & January 2008 & 13.5 & $0.60(0.52-0.68)$ & 0.08 \\
& Forest & November 2007 & 2.8 & $2.90(2.11-3.30)$ & 0.08 \\
\hline
\end{tabular}


Table 5 Parous rate, probability of daily survival, life expectancy (days) and vectorial capacity of Anopheles cracens in study areas

\begin{tabular}{lll}
\hline & Fruit Orchard & Forest \\
\hline Parous rate $(95 \% \mathrm{Cl})$ & $65.7(62.0-69.4)$ & $71.5(65.9-77.1)$ \\
Probability of daily survival - p & 0.87 & 0.89 \\
p10 (\%) & 25 & 31 \\
$\begin{array}{l}\text { Life Expectancy p10/-loge } \\
\text { (days) }(1 / \text {-In p) }\end{array}$ & 7.2 & 8.6 \\
Vectorial Capacity & 2.46 & 1.09 \\
\hline
\end{tabular}

is evident that more studies on vectors are needed throughout Malaysia in order to understand the dynamics of simian malaria being transmitted to humans.

Laboratory studies have shown both $A n$. kochi and $A n$. maculatus are susceptible to simian malaria parasites especially to $P$. cynomolgi [21]. However, the numbers of $A n$. maculatus coming to the monkey-bait trap was very scarce and this could be a reason why An. maculatus has not been found with natural infection of simian malaria. As for An. kochi, it was found predominantly at ground level and not at canopy level and this could be one of the reasons why it was not positive for sporozoites. In nature the macaques roost on trees at night and thus mosquitoes biting at canopy level will be able to pick up infection.

Although knowlesi malaria has been reported from many countries in Southeast Asia, studies on vectors in relation to knowlesi malaria are lacking. Besides Malaysia, studies in Vietnam have incriminated Anopheles dirus to be the vector of P. knowlesi [48,49]. In Vietnam $A n$. dirus has been found positive with mixed infection of human and simian malaria sporozoites. However, cases of knowlesi malaria in Vietnam was cryptic and only a few cases have been reported [8], while in Malaysia, mixed infection of human and simian malaria occurs $[2,3]$ but no mixed infection was found in An. cracens. This leads to further gaps in our knowledge with regard to human to human transmission or monkey to human

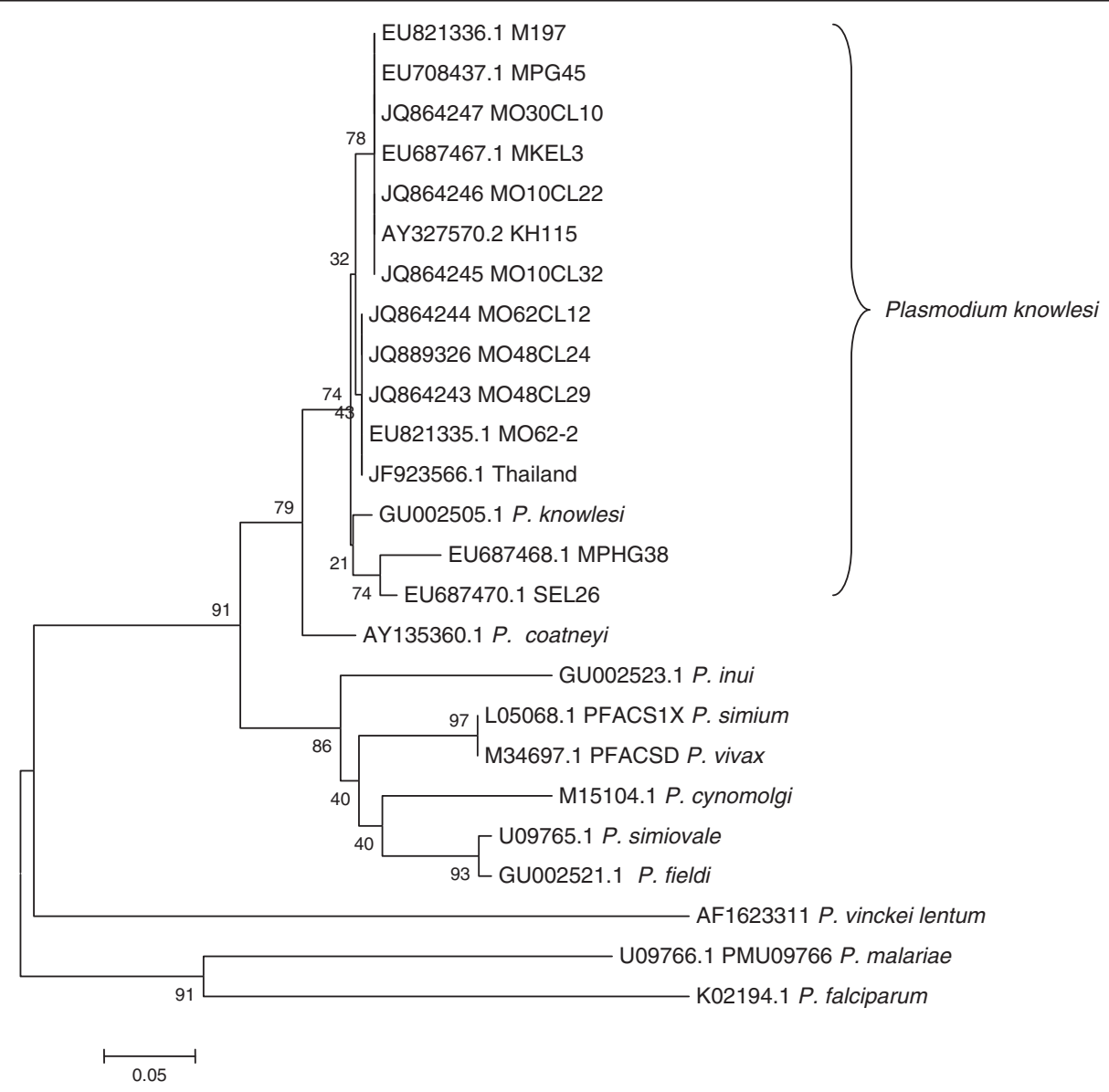

Figure 3 Phylogenetic tree based on csp sequences of Plasmodium spp. JQ864243, JQ864244, JQ864245, JQ864246 JQ864247 and JQ889326 are $P$. knowlesi csp sequences obtained in this study. The tree is constructed using neighbour joining method MEGA4 [34]. The percentage of replicate trees in which the associated isolates cluster together in the bootstrap test (1,000 replicates) are shown next to the branches. 
transmission. In the case of Malaysia, deforestation has certainly disrupted the ecosystem and the forest mosquitoes that were found in the northern part only of peninsular Malaysia is now reported in the east coast of the peninsular and were found in the edge of the forest and in villages surrounding the forest. How much further they have spread remains unknown. It is also difficult to decipher why the numbers of An. cracens were more in the fruit orchard compared to the forest edge. With deforestation this species of mosquito is still able to colonise the plantations and the forest edge. It seems similar to a report in Thailand where by An. dirus a forest mosquito colonised plantations when deforestation took place [50]. Since cases of knowlesi malaria have been reported from all states of Malaysia, vectors must be present everywhere. However, a species may play a primary role in an area and a secondary role elsewhere. Thus, vector control activities will be hampered unless vectors are elucidated throughout the country. In order to eliminate malaria in Malaysia it is important to study the vectors in various ecological zones so as to design an effective control programme. From this study it is also clear that current vector control tools being used in the malaria control programme will not be effective to reduce vector population as these mosquitoes are exophagic and early biters. Extensive studies should also be carried out on village population to determine the prevalence of knowlesi malaria in the country. Besides microscopy, molecular techniques should be used in order to determine the species of malaria. Only then can proper strategies be instituted to control malaria and work towards its elimination.

Molecular techniques are very useful in identifying the infection, in describing the epidemiology, and in characterizing mixed infections, which are otherwise under reported. Thus, with the improvement in molecular diagnostics methods, one is now able to distinguish between P. knowlesi and P. malariae. However, the levels of the problem strongly rely on the cohabitation of the monkeys, humans and the presence of the vectors, which are simio-anthropophagic and exophilic. The frequency of man-monkey-mosquito natural cycle transmission is dependent upon the various hosts in the area of natural transmission.

\section{Conclusion}

This study has confirmed that An. cracens, has the highest vectorial capacity among all the anophelines collected from Kuala Lipis, Pahang. The behavioural studies revealed that An. cracens is simio-anthropophagic, acrodendrophilic towards the later part of the night and is the natural vector of $P$. knowlesi and other simian malaria parasites. Identification of vectors involved in the transmission of $P$. knowlesi to humans has been established and this should lead to the appropriate control strategies for elimination of malaria as the indoor residual spraying and insecticide-treated bed nets are insufficient to control the vectors of simian malaria due to the strong exophilic and exophagic nature of the vector. Thus, there is an urgency for similar studies to be carried out in other states of Malaysia as cases of knowlesi malaria are reported throughout the country and the vectors responsible remain unknown in most states of Malaysia.

\section{Competing interests}

The authors declare that they have no competing interests.

\section{Authors' contributions}

IV conceived the study. AIJ, IV and FMY were responsible for the preparation of the manuscript. IV, AIJ, NAY, YY and AAH were responsible for field collection, supervision, identification and processing of mosquitoes. AlJ and IV were responsible for the molecular work. AIJ, FMY and IV analysed sequence data. All authors have read and approved the manuscript.

\section{Acknowledgements}

The authors would like to thank Dr Rahimi Hassan and the staff of Vector Borne Disease Control Program, Kuala Lipis, for their assistance in collection of mosquitoes; Mr S Subramaniam from Entomology Unit, IMR for his contribution in collecting and dissecting the mosquitoes; staff of Parasitology Unit, IMR for their help in field and laboratory work; Director General of the Wild Life Department Malaysia for permission to trap monkeys; Head of Parasitology Unit,IMR for her support; Director General of Health Malaysia and Director of IMR for permission to publish. This project was supported by a grant from the National Institute of Health Malaysia "06 CAM 04-06" and Grant No HIR/099 from University of Malaya. This work formed a part of the graduate study (MSc) of AIJ at University of Malaya, Kuala Lumpur, Malaysia.

\section{Author details}

${ }^{1}$ Parasitology Unit, Infectious Diseases Research Centre, Institute for Medical Research, Jalan Pahang, 50588, Kuala Lumpur, Malaysia. ${ }^{2}$ Parasitology Department, Faculty of Medicine, University of Malaya, 50603, Kuala Lumpur, Malaysia. ${ }^{3}$ Entomology Unit, Infectious Diseases Research Centre, Institute for Medical Research, Jalan Pahang, 50588, Kuala Lumpur, Malaysia.

Received: 24 April 2012 Accepted: 14 June 2012

Published: 22 June 2012

\section{References}

1. Cox Singh J, Davis TME, Lee KS, Shamsul SSG, Matusop A, Ratnam S, Rahman HA, Conway DJ, Singh B: Plasmodium knowlesi malaria in humans is widely distributed and potentially life threatening. Clin Infect Dis 2008, 46:165-171.

2. Singh B, Sung LK, Matusop A, Radhakrishnan A, Shamsul SSG, Cox-Singh J, Thomas A, Conway DJ: A large focus of naturally acquired Plasmodium knowlesi infections in human beings. Lancet 2004, 363:1017-1024.

3. Vythilingam I, NoorAzian YM, Huat TC, Jiram Al, Yusri YM, Azahari AH, NorParina I, NoorRain A, LokmanHakim S: Plasmodium knowlesi in humans, macaques and mosquitoes in peninsular Malaysia. Parasit Vectors 2008, $1: 26$.

4. William T, Menon J, Rajahram G, Chan L, Ma G, Donaldson S, Khoo S, Fredrick C, Jelip J, Anstey NM: Severe Plasmodium knowlesi malaria in a tertiary care hospital, Sabah, Malaysia. Emerg Infect Dis 2011, 17:1248-1254.

5. Jongwutiwes S, Putaporntip C, Iwasaki T, Sata T, Kanbara H: Naturally acquired Plasmodium knowlesi malaria in human, Thailand. Emerg Infect Dis 2004, 10:2211-2213.

6. Ng OT, Ooi EE, Lee CC, Lee PJ, Ng LC, Pei SW, Tu TM, Loh JP, Leo YS: Naturally acquired human Plasmodium knowlesi infection. Singapore. Emerg Infect Dis 2008, 14:814.

7. Luchavez J, Espino F, Curameng P, Espina R, Bell D, Chiodini P, Nolder D, Sutherland C, Lee KS, Singh B: Human infections with Plasmodium knowlesi, the Philippines. Emerg Infect Dis 2008, 14:811-813. 
8. Eede P, Van H, Van Overmeir C, Vythilingam I, Duc T, Hung L, Manh H, Anné J, D'Alessandro U, Erhart A: Human Plasmodium knowlesi infections in young children in central Vietnam. Malar J 2009, 8:249.

9. Z Zhu H, Li J, Zheng H: [Human natural infection of Plasmodium knowlesi] (in Chinese). Zhongguo Ji Sheng Chong Xue Yu Ji Sheng Chong Bing Za Zhi 2006, 24:70-71.

10. Jiang N, Chang Q, Sun X, Lu H, Yin J, Zhang Z, Wahlgren M, Chen Q: Co-infections with Plasmodium knowlesi and other malaria parasites, Myanmar. Emerg Infect Dis 2010, 16:1476-1478.

11. Sulistyaningsih E, Fitri LE, Löscher T, Berens-Riha N: Diagnostic difficulties with Plasmodium knowlesi infection in humans. Emerg Infect Dis 2010, 16:1033.

12. Khim N, Siv S, Kim S, Mueller T, Fleischmann E, Singh B, Divis P, Steenkeste N, Duval L, Bouchier C: Plasmodium knowlesi infection in humans, Cambodia, 2007-2010. Emerg Infect Dis 1900, 2011:17.

13. Bronner U, Divis PCS, Färnert A, Singh B: Swedish traveller with Plasmodium knowlesi malaria after visiting Malaysian Borneo: a case report. Malar J 2009, 8:15.

14. Kantele A, Marti H, Felger I, Muller D, Jokiranta TS: Monkey Malaria in a European Traveler Returning from Malaysia. Emerg Infect Dis 2008, 14:1434-1436.

15. Mali S, Steele S, Slutsker L, Arguin PM: Malaria surveillance-United states, 2006. MMWR Surveill Summ 2008, 57:24-39.

16. Tang TH, Salas A, Ali-Tammam M, Martínez M, Lanza M, Arroyo E, Rubio J: First case of detection of Plasmodium knowlesi in Spain by Real Time PCR in a traveller from Southeast Asia. Malar J 2010, 9:219.

17. Berry A, Iriart X, Wilhelm N, Valentin A, Cassaing S, Witkowski B, Benoit-Vica F, Menard S, Olagnier D, Fillaux J: Imported Plasmodium knowlesi malaria in a French tourist returning from Thailand. Am JTrop Med Hyg 2011, 84:535-538.

18. Chin W, Contacos PG, Coatney GR, Kimball HR: A naturally acquired quotidian-type malaria in man transferable to monkeys. Science 1965, 149:865.

19. Cheong WH, Warren MW, Omar AH, Mahadevan S: Anopheles balabacensis balabacensis identified as vector of simian malaria in Malaysia. Science 1965, 150:1314.

20. Warren MW, Cheong WH, Fredericks HK, Coatney GR: Cycles of jungle malaria in West Malaysia. AmJTrop Med Hyg 1970, 19:383.

21. Warren MW, Wharton $\mathrm{RH}$ : The vectors of simian malaria: identity, biology, and geographical distribution. J Parasitol 1963, :892-904.

22. Wharton $\mathrm{RH}$, Eyles $\mathrm{DE}$, Warren $\mathrm{M}$, Cheong WH: Studies to determine the vectors of monkey malaria in Malaya Ann Trop Med Parasitol 1964, 58:56.

23. Wharton RH, Eyles DE: Anopheles hackeri, a vector of Plasmodium knowlesi in Malaya. Science 1961, 134:279.

24. Eyles DE, Laing ABG, Dobrovolny CG: The malaria parasites of the pigtailed macaque, Macaca nemestrina (Linnaeus). Indian J Malar 1962, 16:285-298.

25. Eyles DE, Laing ABG, Warren M, Sandosham AA: Malaria parasites of the Malayan leaf monkeys of the genus Presbytis. Med J Malay 1962, 17:85-86.

26. Eyles DE, Laing ABG, Fong YL: Plasmodium fieldi sp nov, a new species of malaria parasite from the pig-tailed macaque in Malaya. Ann Trop Med Parasitol 1962, 56:242-247.

27. Choudhury DS, Wattal BL, Ramakrishnan SP: Incrimination of Anopheles elegans James (1903) as a natural vector of simian malaria in the Nilgiris, madras State. India. Indian J Malar 1963, 17:243.

28. Vythilingam I, Tan CH, Asmad M, Chan ST, Lee KS, Singh B: Natural transmission of Plasmodium knowlesi to humans by Anopheles latens in Sarawak, Malaysia. Trans R Soc Trop Med Hyg 2006, 100:1087-1088.

29. Vythilingam I, Foo LC, Chiang GL, Chan ST, Eng KL, Mahadevan S, Mak JW, Singh Kl: The impact of permethrin impregnated bednets on the malaria vector Anopheles maculatus (Diptera: Culicidae) in aboriginal villages of Pos Betau Pahang, Malaysia. Southeast Asian J Trop Med Pub Health 1995, 26:354-358.

30. Wharton $\mathrm{RH}$, Eyles DE, Warren Mc W: The development of methods for trapping the vectors of monkey malaria. Ann Trop Med Parasitol 1963, 57:32-46.

31. Reid JA: Anopheline Mosquitoes of Malaya and Borneo. Malaysia: Institute for Medical Research Malaysia; 1968.

32. Sallum MAM, Peyton EL, Harrison BA, Wilkerson RC: Revision of the Leucosphyrus group of Anopheles (Cellia)(Diptera, Culicidae). Revista Brasileira de Entomolo 2005, 49:101-152
33. Singh B, Bobogare A, Cox-Singh J, Snounou G, Abdullah MS, Rahman H: A genus- and species-specific nested polymerase chain reaction malaria detection assay for epidemiologic studies. Am JTrop Med Hyg 1999, 60:687-692.

34. Tamura K, Dudley J, Nei M, Kumar S: MEGA4: molecular evolutionary genetics analysis (MEGA) software version 4.0. Mol Biol Evol 2007, 24:1596-1599.

35. Garret-Jones C, Shidrawi GR: Malaria vectorial capacity of a population of Anopheles gambiae, an exercise in epidemiological entomology. Bull World Health Organ 1969, 40:531-545.

36. Subbarao SK: Anopheline species complexes in South and Southeast Asia. India: World Health Org Reg office Southeast Asia; 2007:102pp.

37. Manguin S, Garros C, Dusfour I, Harbach RE, Coosemans M: Bionomics, taxonomy, and distribution of the major malaria vector taxa of Anopheles subgenus Cellia in Southeast Asia: An updated review. Infect Genet Evol 2008, 8:489-503.

38. Sinka ME, Bangs MJ, Manguin S, Chareonviriyaphap T, Patil AP, Temperley WH, Gething PW, Elyazar IRF, Kabaria CW, Harbach RE, Hay SI: The dominant Anopheles vectors of human malaria in the Asia-Pacific region: occurrence data, distribution maps and bionomic précis. Parasit Vectors 2011, 4:1-46.

39. Chang MS, Doraisingam P, Hardin S, Nagum N: Malaria and filariasis transmission in a village/forest setting in Baram District, Sarawak, Malaysia. J Trop Med Hyg 1995, 98:192.

40. Chang MS, Hii J, Buttner P, Mansoor F: Changes in abundance and behaviour of vector mosquitoes induced by land use during the development of an oil palm plantation in Sarawak. Trans $R$ Soc Trop Med Hyg 1997, 91:382-386.

41. Vythilingam I: Review Paper Plasmodium knowlesi in humans: a review on the role of its vectors in Malaysia. Trop Biomed 2010, 27:1-12.

42. Baimai V, Kijchalao U, Sawadwongporn P, Green CA: Geographic distribution and biting behaviour of four species of the Anopheles dirus complex (Diptera: Culicidae) in Thailand. Southeast Asian J Trop Med Pub Health 1988, 19:151-161.

43. Scanlon JE: Ecology of Anopheles vectors of malaria in the Oriental region. Cahiers ORSTOM ser Ent Med 1968, 6:237-246.

44. Chiang GL, Loong KP, Chan ST, Eng KL, Yap HH: Capture-recapture studies with Anopheles maculatus Theobald (Diptera: Culicidae) the vector of malaria in peninsular Malaysia. Southeast Asian J Trop Med Pub Health 1991, 22:643.

45. Rahman WA, Che'Rus A, Ahmad AH: Malaria and Anopheles mosquitos in Malaysia. Southeast Asian J Trop Med Pub Health 1997, 28:599.

46. Sandosham AA, Thomas V: Malariology: with special reference to Malaya. USA: Coronet Books; 1983.

47. Tan CH, Vythilingam I, Matusop A, Chan ST, Singh B: Bionomics of Anopheles latens in Kapit, Sarawak. Malaysian Borneo in relation to the transmission of zoonotic simian malaria parasite Plasmodium knowlesi. Malar J 2008, 7:52.

48. Marchand RP, Culleton R, Maeno Y, Quang NT, Nakazawa S: Co-infections of Plasmodium knowlesi, P. falciparum and P. vivax among humans and Anopheles dirus mosquitoes, southern Vietnam. Emerg Infect Dis 2011, 17:1232-1239.

49. Nakazawa S, Marchand RP, Quang NT, Culleton R, Manh ND, Maeno Y: Anopheles dirus co-infection with human and monkey malaria parasites in Vietnam. Int J Parasitol 2009, 39:1533-1537.

50. Rosenberg R, Andre RG, Somchit L: Highly efficient dry season transmission of malaria in Thailand. Trans R Soc Trop Med Hyg 1990, 84:22-28.

doi:10.1186/1475-2875-11-213

Cite this article as: Jiram et al:: Entomologic investigation of Plasmodium knowlesi vectors in Kuala Lipis, Pahang, Malaysia. Malaria Journal 2012 $11: 213$ 